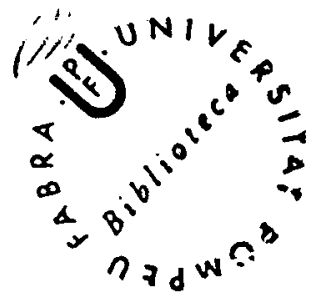

Economics Working Paper $145^{*}$

\title{
Information Revelation and Market Incompleteness ${ }^{\dagger}$
}

\author{
José M. Marin \\ and \\ Rohit Rahi**
}

February $1996^{\dagger \dagger}$

Keywords: Information revelation, incomplete markets, security design, futures contracts.

Journal of Economic Literature classification: D52, D82, G14.

* This paper is also number 8 Finance and Banking Discussion Papers Series, UPF.

${ }^{\dagger}$ Preliminary and incomplete. Comments welcome.

We have benefitted from the feedback of seminar audiences at Bilbao, Birkbeck, Birmingham, and Pompeu Fabra. We would like to acknowledge financial support from the Spanish Ministry of Education (DGICYT grant PB93-0388).

${ }^{\ddagger}$ Universitat Pompeu Fabra. Balmes 132, 08008 Barcelona, Spain. E-mail: marin@upf.es

** Birkbeck College, University of London. 7-15 Gresse Street, London W1P 2LL, U.K. E-mail: rahi@ricardo.econ.bbk.ac.uk

"First draft: November 1995






\begin{abstract}
This paper shows that the presence of private information in an economy can be a source of market incompleteness even when it is feasible to issue a

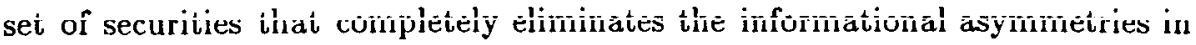
equilibrium. We analyze a simple security design model in which a volume maximizing futures exchange chooses not only the characteristics of each individual contract but also the number of contracts. Agents have rational expectations and differ in information, endowments and, possibly, attitudes toward risk. The emergence of complete or incomplete markets in equilibrium depends on whether the adverse selection effect is stronger or weaker than the Hirshleifer effect, as new securities are issued and prices reveal more information. When the Hirshleifer effect dominates, the exchange chooses an incomplete set of financial contracts, and the equilibrium price is partially revealing.
\end{abstract}




\section{Introduction}

The eighties witnessed the development of an extensive literature on the existence and characterization of equilibrium in economies with incomplete financial markets (see the survey articles by Cass (1992), Duffie (1992), Geanakoplos (1990), and Magill and Shafer (1991)). In this literature, the set of financial instruments is exogenously given and assumed to be incomplete. There is now emerging a grouming tưủy of iesearch on finañial innovation and security design whose main goal is to endogenize the financial structure (for an overview, see Allen and Gale (1994) and Duffie and Rahi (1995)). This literature has identified several motives for innovation, such as the provision of new risk sharing opportunities, the desire to reduce transaction costs or increase liquidity, and the need to circumvent regulations. It has also studied the incentives of various types of innovators, from investment banks securitizing a pool of illiquid assets to exchanges introducing futures and options contracts.

Much of the security design literature takes the number of assets as given, focusing on characterizing an incomplete financial structure, rather than explaining the incompleteness itself. The papers by Demange and Laroque (1995a, 1995b), Duffie and Jackson (1989), Hara (1992), Ōhashi $(1992,1994)$, and Rahi $(1995,1996)$ fall in this category. Papers that do endogenize the number of assets do so by postulating an exogenously given cost of setting up or operating markets (Allen and Gale $(1989,1990,1991)$, Cuny (1993), Pesendorfer (1995)). While market frictions and transaction costs are probably an important element in accounting for incomplete markets, taking them as exogenously given does not lead to a fully satisfactory explanation.

In this paper we eschew the frictions-based approach altogether, and argue that the presence of private information in an economy can be another source of market incompleteness. The connection between security design, asymmetric information, and trading in financial markets is a subtle one, and it is important to isolate its various facets. The efficacy of security markets in aggregating and transmitting private information depends on the characteristics of the financial structure, and especially on the number of tradable assets. Indeed, within the rational expectations paradigm, informational differences disappear in equilibrium (generically) when the price vector has a higher dimensionality than the space of private signals (see Radner (1979), Allen (1986)), i.e. when the number of securities is large enough.

At first glance, one would expect that from the point of view of information aggregation, a greater number of assets would be desirable, and hence created (given the right incentives). 
There is a strong case for this in a production economy in which privately held information impacts on real investment decisions. Rahi (1995) has analyzed a model which supports this intuition, although he is only concerned with the design of a given number of assets. In a pure exchange setting, one might still expect a higher volume of trade the lower the degree of informational asymmetry in equilibrium (Wang (1994)). In fact, a prevailing intuition in finance is that financial markets characterized by private information are much like the market for lemons $a$ la Akerlof (1970). Less informed traders may be unwilling to trade, raising the possibility of even a market breakdown (Bhattacharya, Reny, and Spiegel (1995)). In the security design context, Rahi (1996) has shown that a privately informed entrepreneur, facing rational uninformed outside investors, issues a security that is not sensitive to her information, thus completely eliminating the adverse selection problem. (See also DeMarzo and Duffie (1995).)

However, there is another aspect of information revelation and trade which is been largely neglected in the finance literature. Markets prices may reveal "too much" information, ${ }^{1}$ insofar as early resolution of uncertainty reduces the market's insurance capabilities: the more the information revealed by prices, the smaller is the amount of risk that remains to be shared in the market. Hirshleifer (1971) was the first to point out this fundamental aspect of the economics of information. We build on Hirshleifer's insight to identify conditions under which the solution to the security design problem involves incomplete markets. The choice of financial structure is determined by the amount of information revealed by prices via the interplay of the adverse selection effect and the Hirshleifer effect. In general, while the adverse selection effect makes it desirable to have a higher number of securities, and consequently lesser informational asymmetry across traders, the Hirshleifer effect favors a reduction in the number of assets, since the more is the information revealed, the greater are the insurance opportunities lost.

To formalize the discussion, we analyze a simple model in which agents differ in information, endowments, and possibly attitudes toward risk, but, because of the rational expectations assumption, may have homogeneous beliefs at the time of trade, depending on whether equilibrium prices are fully revealing or not. Given this ex ante heterogeneity, there is an incentive to set up an exchange on which agents can share their risks. In our model, the security designer is a volume maximizing futures exchange. This type of objective function is not new in the literature (see, for example, Duffie and Jackson (1989) and Rahi (1995))

\footnotetext{
1 For a welfare analysis of rational expectations equilibria, see Laffont (1985).
} 
and we believe it a good assumption when confronted with practices in actual markets. For a more detailed discussion, see Black (1986) and Duffie and Rahi (1995). Saloner's (1984) model of the microstructure of futures markets, in which Bertrand competition in brokerage fees between floor traders leads to commonly set commission rates and equal shares of the trading volume, lends theoretical support for the volume maximizing objective.

We mơdel üncentainty in our economy by assuming the existence of several risle facters that affect agents' endowments. Agents are assumed to be rational in the von NeumannMorgenstern sense. We introduce asymmetric information by assuming that a fraction of agents ("informed" traders) have access to a private signal that is correlated with some of the risk factors. We also assume that each agent privately observes the "size" (in a sense to be made precise) of his hedging needs. To summarize the informational structure: each agent has private information on the size of his hedging needs; the informed traders have superior information on the risk factors; everyone has rational expectations.

Given this set up, we can be more specific regarding the meaning of our hypothesis and the main result. The exchange can choose not only the characteristics of each individual security it issues, but also the number of securities. The greater the number of securities introduced, the more precise is the information conveyed by prices. This produces two opposing effects on the level of activity in the futures markets. On the one hand, there is (a reduction in) the adverse selection effect. Since the uninformed agents know the informed agents' private information better, they are more willing to participate in the market to share their initial risks. On the other hand, there is the Hirshleifer effect: the more the information revealed by prices, the smaller is the provision of insurance by markets. As more information is revealed, the riskiness of agents' endowments fall. Since the portion of risk that has already been revealed by prices cannot be traded away in the market, the size of the risk that can be shared is smaller. In the limit case in which the informed traders' private information is perfect (i.e. they know the true state that will occur in the future) and fully revealed by prices, no risk can be shared in the market. This was Hirshleifer's original example.

A way to measure the extent to which markets are used to share risk is to compute trading volume. In this sense, when the exchange maximizes trading volume, it is also maximizing the level of activity, or the provision of insurance, in the market. When the Hirshleifer effect outweighs the adverse selection effect, an incomplete financial structure entails a higher volume of trade (in a partially revealing equilibrium), than would be the 
case with complete markets (and full revelation).

Before we proceed to formalize our argument, we would like to mention one earlier attempt to obtain incomplete markets endogenously in an economy with asymmetric information. $\bar{O}$ hashi (1995) provides an example of a futures exchange choosing a particular index contract in preference to a complete set of assets. He argues that full revelation in the lätter case leads to a lower amount of speculative trade because of the symmetrization of agents' information in equilibrium. It appears to us that $\bar{O}$ hashi 's result depends crucially on the presence of noise traders (who are responsible for partial revelation in the case of a single contract). Indeed, homogeneity of beliefs should lead to a higher volume of trade due to the absence of adverse selection. Irrational noise traders are immune to the adverse selection effect. As far as speculative trade is concerned, it is well known that trade on the basis of informational differences alone is not viable (Milgrom and Stokey (1982)).

The rest of the paper is organized as follows. In Section 2 we set up the model. In Section 3 we compute the equilibrium for the case in which the exchange chooses a single futures contract which is an index of the risk factors. We study the complete markets case, with a contract corresponding to each factor, in Section 4 . Section 5 is dedicated to comparing trading volume in the two economies and to precisely stating the conditions under which the exchange is better off issuing a single index contract. Finally, we reserve Section 7 for conclusions and for a discussion of some extensions of our model.

\section{The Model}

We use the exponential-normal framework described in the survey article by Duffie and Rahi (1995). The setting is a single-good economy with uncertainty and two types of asymmetrically informed agents with risky endowments. These agents have access to (possibly incomplete) futures markets that allow some risk-sharing and aggregation of information. The sequence of events is as follows: At the ex ante stage the collection of tradable futures contracts is determined by a futures exchange. At the interim stage agents observe their private signals and trade the available securities in a competitive rational expectations equilibrium. Finally, at the ex post stage, all uncertainty is resolved, the futures contracts are settled, and agents consume.

A trader of type $i$ has a von Neumann-Morgenstern utility function with constant absolute risk aversion $r_{i}$. With this assumption, traders of a particular type can be aggregated into a representative agent. Therefore, we will henceforth refer to a type $i$ agent simply as 
agent $i$. Let $^{2} \mathrm{z}:=\left(z_{1}, z_{2}\right)^{\top}$ and $\mathrm{x}:=\left(x_{1}, x_{2}\right)^{\top}$ be independent normal random vectors, ${ }^{3}$ with

$$
\mathbf{z} \sim N(\mathbf{0}, \mathrm{I}) \quad \text { and } \quad \mathbf{x} \sim N\left[\left(\begin{array}{l}
0 \\
0
\end{array}\right),\left(\begin{array}{ll}
1 & \rho_{x} \\
\rho_{x} & 1
\end{array}\right)\right] .
$$

The initial endowment of agent $i$ is $e_{i}:=x_{i} \mathbf{k}_{i}^{\top} z$, where $\mathbf{k}_{i}:=\left(k_{i 1}, k_{i 2}\right)^{\top}$ is a coefficient vector in $\mathbb{R}^{2}$. Here $x_{i}$, assumed to be (privately) known to agent $i$ at the time of trading, can be thought of as the size of agent $i$ 's hedging needs, and $z$ an orthonormal basis for the agents' (normalized) endowments. By an appropriate choice of units we can normalize the variance of the $x_{i}$ 's to be one, so that $\rho_{x}$ is their correlation coefficient. In addition to $x_{1}$ agent 1 observes a normally distributed private signal $s$ correlated with the second risk factor $z_{2}$ (and independent of all other random variables). ${ }^{4}$ We can take the signal $s$ to be standard normal without loss of generality, and write

$$
z_{2}=\rho s+y
$$

where $\rho$ is the correlation coefficient between $z_{2}$ and $s$, and $y$ is a residual uncorrelated with $s$.

Given these primitives, we consider two different financial structures. In the first, the exchange issues a single index future contract that includes both risk factors, while in the second the exchange issues two sigled-factor securities. In the next two sections we separately analyze the equilibrium in each of these financial structures.

\section{The One-Asset Economy}

Suppose there is a single index futures contract with payoff $f$ :

$$
f=\mathbf{a}^{\top} \mathbf{z}+\epsilon,
$$

where $\mathbf{a}:=\left(a_{1}, a_{2}\right) \in \mathbb{R}^{2}$, with $\|\mathbf{a}\|=1$, and $\epsilon$ is a normally distributed mean zero extraneous noise term independent of all other random variables. The norm condition on

2 Matrices, vectors, and vector-valued random variables are distinguished by boldface type. The symbol ${ }^{\top}$ denotes transpose.

${ }^{3}$ All random variables are defined on a fixed probability space $(\Omega, \mathcal{F}, P)$. All normally distributed random variables belong to a linear space $\mathcal{N}$ of joint normally distributed random variables on $\Omega$, endowed with an inner product in the usual way: For $g, h \in \mathcal{N},(g \mid h):=\operatorname{cov}(g, h)$.

4 This is not as special as it seems since we can choose the basis $z$ in such a way as to ensure that one of the risk factors is uncorrelated with $s$. 
the coefficient vector $\mathbf{a}$ is merely a normalization of the size of the futures contract. The noise term $\epsilon$ can be thought of as uncertainty in the futures settlement technology, or simply as a modeling device. In fact, it plays no role in the one-asset economy, and is introduced here just to facilitate comparison with the two-asset case. We will comment on this in Section 5. For the present it suffices to note that the results of the paper hold regardless of the siże of the nouvise, as long as it is nondegenerate. A futures position $\theta_{i}$ leaves agent $i$ with net wealth

$$
w_{i}:=e_{i}+\theta_{i}(f-p)
$$

where $p$ is the asset price.

The information set of agent 1 is $\mathcal{I}_{1}:=\left(s, x_{1}, p\right)$, and that of agent 2 is $\mathcal{I}_{2}:=\left(x_{2}, p\right)$. Agent $i$ faces the following optimization problem:

$$
\max _{\theta_{i} \in \mathcal{M}_{i}} E\left[-\exp \left(-r_{i} w_{i}\right)\right]
$$

where $w_{i}$ is given by (4), and $\mathcal{M}_{i}$ is the space of $\mathcal{I}_{i}$-measurable random variables. Conditional on $\mathcal{I}_{i}$, any choice of $\theta_{i}$ leaves net wealth $w_{i}$ normally distributed. ${ }^{5}$ Therefore, agent $i$ 's expected utility is

$$
\begin{aligned}
E\left[-\exp \left(-r_{i} w_{i}\right)\right] & =-E\left[E\left[\exp \left(-r_{i} w_{i}\right) \mid \mathcal{I}_{i}\right]\right] \\
& =-E\left[\exp \left(-r_{i}\left[E\left(w_{i} \mid \mathcal{I}_{i}\right)-\frac{r_{i}}{2} \operatorname{Var}\left(w_{i} \mid \mathcal{I}_{i}\right)\right]\right)\right]
\end{aligned}
$$

Let

$$
\mathcal{E}_{i}:=E\left(w_{i} \mid \mathcal{I}_{i}\right)-\frac{r_{i}}{2} \operatorname{Var}\left(w_{i} \mid \mathcal{I}_{i}\right)
$$

The problem (5) reduces to choosing an asset position $\theta_{i}$ to maximize $\mathcal{E}_{i}$ pointwise for each realization of the information $\mathcal{I}_{i}$. From (4) and (7):

$$
\mathcal{E}_{i}=E\left(e_{i} \mid \mathcal{I}_{i}\right)+\theta_{i}\left[E\left(f \mid \mathcal{I}_{i}\right)-p\right]-\frac{r_{i}}{2}\left[\operatorname{Var}\left(e_{i} \mid \mathcal{I}_{i}\right)+\theta_{i}^{2} \operatorname{Var}\left(f \mid \mathcal{I}_{i}\right)+2 \theta_{i} \operatorname{cov}\left(f, e_{i} \mid \mathcal{I}_{i}\right)\right]
$$

The solution to (5) is now easily obtained:

$$
\theta_{i}=\frac{E\left(f \mid \mathcal{I}_{i}\right)-p-r_{i} \operatorname{cov}\left(f, e_{i} \mid \mathcal{I}_{i}\right)}{r_{i} \operatorname{Var}\left(f \mid \mathcal{I}_{i}\right)}
$$

\footnotetext{
5 Assuming that $p$ is in $\mathcal{N}$, which will indeed be the case in the equilibrium we study.
} 
We use "hats" and "tildes" to denote moments conditional on $\mathcal{I}_{1}$ and $\mathcal{I}_{2}$ respectively. For example, for random variables $g$ and $h, \hat{E}_{g}:=E\left(g \mid \mathcal{I}_{1}\right)$, and $\tilde{V}_{g h}:=\operatorname{cov}\left(g, h \mid \mathcal{I}_{2}\right)$. Then ${ }^{6}$

$$
\begin{aligned}
& \theta_{1}=\frac{\mathbf{a}^{\top} \hat{\mathbf{E}}_{\mathbf{z}}-p-r_{1} x_{1} \mathbf{a}^{\top} \hat{\mathbf{V}}_{\mathbf{z}} \mathbf{k}_{1}}{r_{1}\left(\mathbf{a}^{\top} \hat{\mathbf{V}}_{\mathbf{z}} \mathbf{a}+V_{\epsilon}\right)} \\
& \theta_{2}=\frac{\mathbf{a}^{\top} \tilde{\mathbf{E}}_{\mathbf{z}}-p-r_{2} x_{2} \mathbf{a}^{\top} \tilde{\mathbf{V}}_{\mathbf{z}} \mathbf{k}_{2}}{r_{2}\left(\mathbf{a}^{\top} \tilde{\mathbf{V}}_{\mathbf{z}} \mathbf{a}+V_{\epsilon}\right)}
\end{aligned}
$$

Definition 1. A linear rational expectations equilibrium for the one-asset economy is a 3-tuple of random variables $\left(\theta_{1}, \theta_{2}, p\right)$, such that $p$ is of the form:

$$
p=\alpha_{1} x_{1}+\alpha_{2} x_{2}+\beta s, \quad\left(\alpha_{1}, \alpha_{2}, \beta\right) \in \mathbb{R}^{3}
$$

given this price function, $\theta_{i}$ solves the utility maximization problem (5) for $i=1,2$; and markets clear for every realization of private information:

$$
\theta_{1}+\theta_{2}=0
$$

In the Appendix we show that there exists a unique linear rational expectations equilibrium. In general this equilibrium is partially revealing. Agent 2 cannot unravel the information signal $s$ (which is relevant to both his endowment and the asset payoff) by observing the equilibrium price. Given that he knows the size of his own endowment, $x_{2}$, he can only infer a linear combination of agent 1's private signals, $x_{1}$ and $s$.

Let

$$
\mu:=\frac{a_{2}}{a_{1}}, \quad \overline{\mathbf{a}}:=\frac{1}{a_{1}} \mathrm{a}=\left(\begin{array}{l}
1 \\
\mu
\end{array}\right) .
$$

Given our normalization $\|\mathbf{a}\|=1$, the ratio $\mu$ is the only security design parameter.

\section{The Two-Asset Economy}

Now suppose there is a separate market for each risk factor. The security payoff vector is:

$$
\mathbf{f}=\mathbf{z}+\epsilon,
$$

where $\epsilon:=\left(\epsilon_{1}, \epsilon_{2}\right)^{\top} \sim N\left(\mathbf{0}, V_{\epsilon} \mathbf{I}\right)$. We denote the futures position of agent $i$ by $\Theta_{i}:=$ $\left(\theta_{i 1}, \theta_{i 2}\right)^{\top}$. The futures price vector is $\mathbf{p}$. Then the net wealth of agent $i$ is given by

$$
w_{i}:=e_{i}+\Theta_{i}^{\top}(\mathbf{f}-\mathbf{p}),
$$

6 We use the following notational convention for covariance matrices: $\left(\mathrm{V}_{\mathrm{g}}\right)_{i j}:=\operatorname{cov}\left(g_{i}, g_{j}\right)$, $\left(\mathbf{V}_{\mathbf{g h}}\right)_{i j}:=\operatorname{cov}\left(g_{i}, h_{j}\right)$, and, for univariate $g$, the $j$ 'th component of the column vector $\mathbf{V}_{g \mathbf{h}}$ is $\operatorname{cov}\left(g, h_{j}\right)$. 
and she solves

$$
\max _{\Theta_{i} \in \mathcal{M}_{i}^{2}} E\left[-\exp \left(-r_{i} w_{i}\right)\right]
$$

As before, conditional on agent $i$ 's information set $\mathcal{I}_{i}$, any choice of portfolio leaves net wealth normally distributed, so that the optimization problem (17) is equivalent to pointwise maximization of the mean-variance criterion (7). In this case,

$$
\mathcal{E}_{i}=E\left(e_{i} \mid \mathcal{I}_{i}\right)+\Theta_{i}^{\top}\left[E\left(\mathbf{f} \mid \mathcal{I}_{i}\right)-\mathbf{p}\right]-\frac{r_{i}}{2}\left[\operatorname{Var}\left(e_{i} \mid \mathcal{I}_{i}\right)+\Theta_{i}^{\top} \operatorname{Var}\left(\mathbf{f} \mid \mathcal{I}_{i}\right) \Theta_{i}+2 \Theta_{i}^{\top} \operatorname{cov}\left(\mathbf{f}, e_{i} \mid \mathcal{I}_{i}\right)\right]
$$

The optimal portfolio is, therefore, given by

$$
\Theta_{i}=\frac{1}{r_{i}} \operatorname{Var}\left(\mathbf{f} \mid \mathcal{I}_{i}\right)^{-1}\left[E\left(\mathbf{f} \mid \mathcal{I}_{i}\right)-\mathbf{p}-r_{i} \operatorname{cov}\left(\mathbf{f}, e_{i} \mid \mathcal{I}_{i}\right)\right]
$$

Definition 2. A linear rational expectations equilibrium for the two-asset economy is a 3-tuple of $\mathbb{R}^{2}$-valued random variables $\left(\Theta_{1}, \Theta_{2}, \mathbf{p}\right)$, such that $\mathbf{p}$ is of the form:

$$
\mathbf{p}=\alpha \mathbf{x}+\beta s
$$

where $\alpha$ is a $2 \times 2$ nonsingular matrix and $\beta$ is a $2 \times 1$ matrix; given this price function, $\Theta_{i}$ solves the utility maximization problem (17) for $i=1,2$; and markets clear for every realization of private information:

$$
\Theta_{1}+\Theta_{2}=0
$$

Such an equilibrium is fully revealing: In equilibrium $\mathcal{I}_{1}=\mathcal{I}_{2}=\left(s, x_{1}, x_{2}\right)$. The next lemma asserts the existence of such an equilibrium and gives the agents' equilibrium portfolio.

LEMмA 4.1. There exists a unique linear rational expectations equilibrium for the two-asset economy. The equilibrium price function is

$$
\mathbf{p}=\hat{\mathbf{E}}_{\mathbf{f}}-\frac{r_{1} r_{2}}{r_{1}+r_{2}} \cdot\left[\hat{\mathbf{V}}_{\mathbf{f} e_{1}}+\hat{\mathbf{V}}_{\mathbf{f} e_{2}}\right]
$$

and the equilibrium asset demands are

$$
\Theta_{i}=\frac{1}{r_{1}+r_{2}} \cdot \hat{\mathbf{V}}_{\mathbf{f}}^{-1}\left[r_{j} \hat{\mathbf{V}}_{\mathbf{f} e_{j}}-r_{i} \hat{\mathbf{V}}_{\mathbf{f} e_{i}}\right], \quad i=1,2, \quad j \neq i
$$


Proof. Substituting the optimal portfolios from (19) in the market clearing condition (21), we can solve for the price function. Substituting this price function back into (19) gives us the equilibrium asset demands.

Now we can compare trading volume in both economies.

\section{Trading Volume}

The expected volume of trade in the one-asset economy is $\mathcal{V}:=E\left(\left|\theta_{1}\right|+\left|\theta_{2}\right|\right)$, while in the two-asset economy it is $\mathcal{V}^{*}:=E\left(\sum_{i, j}\left|\theta_{i j}\right|\right)$. Trading volume depends on the heterogeneity in agents' endowments. Let

$$
h_{j}:=r_{1} k_{1 j} x_{1}-r_{2} k_{2 j} x_{2}, \quad j=1,2
$$

The random variable $h_{j}$ is the ex ante risk adjusted heterogeneity in agents' endowments of factor $j$.

LEMMA 5.1. The equilibrium expected trading volume in the two-asset economy is

$$
\mathcal{V}^{*}=2 \sqrt{\frac{2}{\pi}} \cdot \frac{1}{r_{1}+r_{2}} \cdot\left[\frac{\operatorname{sdev}\left(h_{1}\right)}{1+V_{\epsilon}}+V_{y} \frac{\operatorname{sdev}\left(h_{2}\right)}{V_{y}+V_{\epsilon}}\right]
$$

Proof. It is straightforward to deduce from the Lemma 4.1 that

$$
\begin{aligned}
& \theta_{11}=-\frac{h_{1}}{\left(r_{1}+r_{2}\right)\left(1+V_{\epsilon}\right)}, \\
& \theta_{12}=-\frac{V_{y} h_{2}}{\left(r_{1}+r_{2}\right)\left(V_{y}+V_{\epsilon}\right)} .
\end{aligned}
$$

In equilibrium $\left|\theta_{1 j}\right|=\left|\theta_{2 j}\right|, j=1,2$. Furthermore, if $X \sim N\left(0, \sigma^{2}\right)$, then $E(|X|)=$ $(2 / \pi)^{\frac{1}{2}} \sigma$. The result follows.

The expression for total volume in the lemma is the sum of two terms, corresponding respectively to the volume of trade in the two markets. The relevant informational parameter is $V_{y}$, which measures the residual uncertainty regarding $z_{2}$ (for both agents, since equilibrium is fully revealing). Indeed, $V_{y}$ parametrizes the Hirshleifer effect. Volume in the second market is monotonically increasing in this parameter. It is zero when $V_{y}$ is zero (or, equivalently, when $\rho=1$ ), which is the "pure" Hirshleifer effect, i.e. the complete 
elimination of trade when there is perfect information. The noise in the second market $\epsilon_{2}$ ensures that trading volume in this market is continuous with respect to $V_{y}$. Without the noise term we get a discontinuity at $V_{y}=0$. This discontinuity disappears when $\epsilon_{2}$ is nondegenerate, no matter how small its variance is.

Volume in the one-asset case, on the other hand, is not susceptible to such a transparent anaiysis, since equilivioum is not fully revealing in general. A useful benchmark, however, is when $\mu=V_{y}=0$, i.e. when the informed agent has perfect information on the second risk factor and the asset payoff in the one-asset economy depends only on the first risk factor. The two economies are essentially identical in this case, with no trading on account of factor 2. In particular, we have:

LEMMA 5.2. If $\mu=V_{y}=0$,

$$
\mathcal{V}=\mathcal{V}^{*}=2 \sqrt{\frac{2}{\pi}} \cdot \frac{\operatorname{sdev}\left(h_{1}\right)}{\left(r_{1}+r_{2}\right)\left(1+V_{\epsilon}\right)}
$$

Proof. Immediate from Lemma 5.1 and Lemma A.2 (in the Appendix).

Now we perturb the one-asset economy, starting from the benchmark.

LEMMA 5.3.

$$
\left(\frac{\partial \mathcal{V}}{\partial \mu}\right)_{\mu=0, V_{y}=0}=-2 \sqrt{\frac{2}{\pi}} \cdot \frac{\operatorname{cov}\left(h_{1}, r_{2} k_{22} x_{2}\right)}{\left(r_{1}+r_{2}\right)\left(1+V_{\epsilon}\right) \operatorname{sdev}\left(h_{1}\right)}
$$

Proof. Immediate from Lemma A.2.

Putting a small positive weight on the second risk factor increases trading volume if (and only if) $\operatorname{cov}\left(h_{1}, r_{2} k_{22} x_{2}\right)$ is negative. To interpret this result, note that agent 1 has no hedging need (at the interim stage) with respect to factor 2 , since she has perfect information regarding this factor. However, with an index futures contract the equilibrium is partially revealing, so that agent 2 would want to trade factor 2 . Since the two factors cannot be traded separately, the question is whether or not trading motivated by factor 2 risk goes in the same direction as that which is already taking place on account of factor 1 . If $h_{1}$, the $e x$ ante heterogeneity in factor 1 , is high, agent 2 takes a long position in the asset on average. If, in addition, his $e x$ ante risk adjusted endowment of factor 2 is negatively 
correlated with $h_{1}$, he would want (on average) to buy the asset in order to increase his exposure to factor 2 . On the other hand, if his factor 2 endowment is positively correlated with $h_{1}$, his desire to take a short position in factor 2 and a long position in factor 1 would tend to coincide, reducing the size of his position in the index.

Let us assume that $\operatorname{cov}\left(h_{1}, r_{2} k_{22} x_{2}\right)$ is nonzero. ${ }^{7}$ Then trading an index always generates higher volume than in the veñchmark case. In the benchmark case, however, the market for the second asset is inactive in the two-asset economy. This raises a conceptual difficulty in that we have agent 2 inferring agent 1 's information from a price in a market in which no trade takes place. If, on the other hand, agent 1's information about the second factor is not perfect there will be trading in both markets, and the total volume may well exceed that with the index. At the benchmark, we have

LEMMA 5.4.

$$
\left(\frac{\partial \mathcal{V}^{*}}{\partial V_{y}}\right)_{\mu=0, V_{\nu}=0}=2 \sqrt{\frac{2}{\pi}} \cdot \frac{\operatorname{sdev}\left(h_{2}\right)}{\left(r_{1}+r_{2}\right) V_{\epsilon}}
$$

Proof. Immediate from Lemma 5.1.

Thus the volume of trade in the two-asset economy goes up (from the benchmark) in the absence of perfect information about factor 2. But volume is continuous in the precision of the informed agent's signal. Provided this signal is sufficiently precise, trading volume in the one-asset economy will be higher than with trading the factors separately. Let us regard the volume of trade (in either economy) as a function of $\mu$ and $V_{y}$, defined on $(-\infty, \infty) \times[0,1]$

THEOREM 5.5. There exists a neighborhood of $(0,0)$ such that $\mathcal{V}>\mathcal{V}^{*}$, for all $\left(\mu, V_{y}\right)$ in this neighborhood satisfying

$$
\operatorname{sgn}(\mu)=-\operatorname{sgn}\left[\operatorname{cov}\left(h_{1}, r_{2} k_{22} x_{2}\right)\right]
$$

and

$$
\frac{|\mu|}{V_{y}}>\frac{1+V_{\epsilon}}{V_{\epsilon}} \cdot \frac{\operatorname{sdev}\left(h_{1}\right) \operatorname{sdev}\left(h_{2}\right)}{\left|\operatorname{cov}\left(h_{1}, r_{2} k_{22} x_{2}\right)\right|}
$$

7 Note that $\operatorname{cov}\left(h_{1}, r_{2} k_{22} x_{2}\right)=r_{2} k_{22}\left(r_{1} k_{11} \rho_{x}-r_{2} k_{21}\right)$, so that the assumed condition holds for an open dense subset of agents' endowments parametrized by $\left(k_{1}, k_{2}\right)$. 
Proof. Note first that

$$
\left(\frac{\partial \mathcal{V}}{\partial V_{y}}\right)_{\mu=0, V_{y}=0}=\left(\frac{\partial \mathcal{V}^{*}}{\partial \mu}\right)_{\mu=0, V_{y}=0}=0
$$

Therefore, evaluated at the benchmark,

$$
d\left(\mathcal{V}-\mathcal{V}^{*}\right)=\frac{\partial \mathcal{V}}{\partial \mu} \dot{d} \mu-\frac{\partial \mathcal{V}^{*}}{\partial V_{y}} a^{\prime} V_{y}
$$

The result now follows from Lemmas 5.3 and 5.4.

The reason for condition (25) is apparent from the previous discussion: Volume in the index is amplified if agents want to trade factors in the same direction. The second condition (26) simply requires that the weight on factor 2 in the index be sufficiently high relative to the residual hedging need in the second asset in the two-asset economy that arises when $V_{y}>0$.

An index contract entails a smaller Hirshleifer effect than the two-asset financial structure, since the index does not allow full revelation of private information about endowments. At the same time partial revelation means that the adverse selection effect, which in absent in the two-asset case, comes into play as well. If private information about endowments is very precise $\left(V_{y}\right.$ is small), an appropriately chosen index contract reduces the Hirshleifer effect (relative to the two-asset case) by more than it increases the adverse selection effect, where we measure the size of these effects by their impact on the volume of trade. The above theorem is just a formalization of this statement.

\section{Welfare}

To be completed

\section{Conclusion}

We have shown that the presence of information asymmetrically distributed among agents with rational expectations can be a source of market incompleteness. This result does not depend on the existence of frictions, such as transaction costs or restrictions on short sales. Our analysis of the role of prices in conveying information, as new securities are issued, identifies two main countervailing forces that are relevant for assessing the use of insurance markets. First, the adverse selection effect suggests that the greater the number 
of securities issued, the better, since the equilibrium price is more informative and uninformed traders will be more willing to use the market to share risks. Second, the Hirshleifer effect favors restricting the number of securities, since the less informative prices are, the greater is the amount of unexplained risk and, therefore, the larger the risk that can be shared through markets. Hence, the emergence of complete or incomplete markets in equilibrium is a question of which of these two cffects dominates. When the Hirshleifer effect is strong enough, endogenous incomplete markets arise and the equilibrium price is partially revealing.

There are several natural extensions our model. First, our approach in this paper is minimalist in the sense that we use a simple model structure in which our conjecture is true. The first extension would consist of checking how robust our results are when some of the assumptions are relaxed, while keeping the present parameterized Gaussian economy. The second extension would relate to asking the same type of question in a general equilibrium model with a general specification of the state space, preferences, and endowments. We believe that the first extension is straightforward, but the second one quite ambitious. Note that in order to compute trading volume, we need closed form solutions for the agents' equilibrium demands. In particular, we need to compute equilibrium demands in an economy in which the equilibrium price is partially revealing. It is well known that such constructions are difficult as soon as we deviate from the Gaussian framework.

Another, perhaps more important, extension would be to do welfare analysis in the present economy. While most of the asymmetric information finance literature uses the noisy rational expectations approach, our model has the virtue of assuming that all agents are fully rational. This is an obvious advantage when it comes to welfare analysis. In particular, we are interested in finding out who profits, the informed or the uninformed traders, for each possible choice of financial structure by the exchange. For instance, we would like to know whether the choice of an incomplete market structure, because of a strong Hirshleifer effect, benefits the informed traders, the uninformed traders, or both, when compared with the complete markets case. This analysis is interesting in its own right but also because it opens a new set of issues. For example, since not all the active traders in a particular market are members (or owners) of the exchange, one issue we would like to study is the theoretical link between the exchange's ownership and its security design policy. All these are problems we are currently working on and we believe we will be able to provide some results not only on the normative, but also on the positive side. 


\section{APPENDIX}

It is useful first to calculate some conditional moments for the one-asset economy. Recall that "hats" and "tildes" denote moments with respect to the information sets of agents 1 and 2 respectively. Using (1) and (2), and the standard theory of the multivariate normal distribution (see, for example, Anderson (19̄8j), Ch. î):

$$
\begin{gathered}
\hat{\mathbb{E}}_{\mathbf{z}}=\left(\begin{array}{c}
0 \\
\rho s
\end{array}\right), \quad \hat{\mathbf{V}}_{\mathbf{z}}=\left(\begin{array}{cc}
1 & 0 \\
0 & 1-\rho^{2}
\end{array}\right) \\
\tilde{\mathbf{E}}_{\mathbf{z}}=\left(\begin{array}{c}
0 \\
\frac{\beta \rho\left[p-\left(\alpha_{1} \rho_{x}+\alpha_{2}\right) x_{2}\right]}{\alpha_{1}^{2}\left(1-\rho_{x}^{2}\right)+\beta^{2}}
\end{array}\right), \quad \tilde{\mathbf{V}}_{\mathbf{z}}=\hat{\mathbf{V}}_{\mathbf{z}}+\left(\begin{array}{cc}
0 & 0 \\
0 & \frac{\alpha_{1}^{2} \rho^{2}\left(1-\rho_{x}^{2}\right)}{\alpha_{1}^{2}\left(1-\rho_{x}^{2}\right)+\beta^{2}}
\end{array}\right)
\end{gathered}
$$

For convenience in handling long algebraic expressions we define:

$$
\begin{aligned}
D:= & \left(r_{1}+r_{2}\right)\left(\mathbf{a}^{\top} \hat{\mathbf{V}}_{\mathbf{z}} \mathbf{a}+V_{\epsilon}\right)\left[r_{1}^{2}\left(1-\rho_{x}^{2}\right)\left(\mathbf{a}^{\top} \hat{\mathbf{V}}_{\mathbf{z}} \mathbf{k}_{1}\right)^{2}+a_{2}^{2} \rho^{2}\right]+r_{1}^{2} r_{2} a_{2}^{2} \rho^{2}\left(1-\rho_{x}^{2}\right)\left(\mathbf{a}^{\top} \hat{\mathbf{V}}_{\mathbf{z}} \mathbf{k}_{1}\right)^{2}, \\
\bar{D}:= & \left(r_{1}+r_{2}\right)\left[\overline{\mathbf{a}}^{\top} \hat{\mathbf{V}}_{\mathbf{z}} \overline{\mathbf{a}}+\left(1+\mu^{2}\right) V_{\epsilon}\right]\left[r_{1}^{2}\left(1-\rho_{x}^{2}\right)\left(\overline{\mathbf{a}}^{\top} \hat{\mathbf{V}}_{\mathbf{z}} \mathbf{k}_{1}\right)^{2}+\mu^{2} \rho^{2}\right] \\
& +r_{1}^{2} r_{2} \mu^{2} \rho^{2}\left(1-\rho_{x}^{2}\right)\left(\overline{\mathbf{a}}^{\top} \hat{\mathbf{V}}_{\mathbf{z}} \mathbf{k}_{1}\right)^{2}, \\
Q:= & r_{1}^{2} r_{2}\left(1-\rho_{x}^{2}\right) \mathbf{a}^{\top} \mathbf{k}_{2}\left(\mathbf{a}^{\top} \hat{\mathbf{V}}_{\mathbf{z}} \mathbf{k}_{1}\right)^{2}+a_{2}^{2} \rho^{2}\left[r_{2} \mathbf{a}^{\top} \hat{\mathbf{V}}_{\mathbf{z}} \mathbf{k}_{2}-r_{1} \rho_{x} \mathbf{a}^{\top} \hat{\mathbf{V}}_{\mathbf{z}} \mathbf{k}_{1}\right], \\
\bar{Q}:= & r_{1}^{2} r_{2}\left(1-\rho_{x}^{2}\right) \overline{\mathbf{a}}^{\top} \mathbf{k}_{2}\left(\overline{\mathbf{a}}^{\top} \hat{\mathbf{V}}_{\mathbf{z}} \mathbf{k}_{1}\right)^{2}+\mu^{2} \rho^{2}\left[r_{2} \overline{\mathbf{a}}^{\top} \hat{\mathbf{V}}_{\mathbf{z}} \mathbf{k}_{2}-r_{1} \rho_{x} \overline{\mathbf{a}}^{\top} \hat{\mathbf{V}}_{\mathbf{z}} \mathbf{k}_{1}\right], \\
R:= & r_{1}\left(\mathbf{a}^{\top} \hat{\mathbf{V}}_{\mathbf{z}} \mathbf{a}+V_{\epsilon}\right)\left[\alpha_{1}^{2}\left(1-\rho_{x}^{2}\right)+\beta^{2}-a_{2} \beta \rho\right]+r_{2}\left(\mathbf{a}^{\top} \hat{\mathbf{V}}_{\mathbf{z}} \mathbf{a}+V_{\epsilon}\right)\left[\alpha_{1}^{2}\left(1-\rho_{x}^{2}\right)+\beta^{2}\right] \\
& +r_{2} a_{2}^{2} \alpha_{1}^{2} \rho^{2}\left(1-\rho_{x}^{2}\right) .
\end{aligned}
$$

Lem мa A.1. There exists a unique linear rational expectations equilibrium for the oneasset economy with

$$
\begin{aligned}
\alpha_{1} & =r_{1} \mathbf{a}^{\top} \hat{\mathbf{V}}_{\mathbf{z}} \mathbf{k}_{1}\left[r_{1}^{3}\left(1-\rho_{x}^{2}\right)\left(\mathbf{a}^{\top} \hat{\mathbf{V}}_{\mathbf{z}} \mathbf{a}+V_{\epsilon}\right)\left(\mathbf{a}^{\top} \hat{\mathbf{V}}_{\mathbf{z}} \mathbf{k}_{1}\right)^{2} D^{-1}-1\right] \\
\alpha_{2} & =-r_{1}\left(\mathbf{a}^{\top} \hat{\mathbf{V}}_{\mathbf{z}} \mathbf{a}+V_{\epsilon}\right) Q D^{-1} \\
\beta & =-\frac{a_{2} \rho \alpha_{1}}{r_{1} \mathbf{a}^{\top} \hat{\mathbf{V}}_{\mathbf{z}} \mathbf{k}_{1}}
\end{aligned}
$$

The equilibrium asset position of agent 1 is:

$$
\theta_{1}=\left(1+\mu^{2}\right)^{\frac{1}{2}} \bar{D}^{-1}\left[r_{1}^{2}\left(1-\rho_{x}^{2}\right)\left(\overline{\mathbf{a}}^{\top} \hat{\mathbf{V}}_{\mathbf{z}} \mathbf{k}_{1}\right)^{2}\left(\mu \rho s-r_{1} x_{1} \overline{\mathbf{a}}^{\top} \hat{\mathbf{V}}_{\mathbf{z}} \mathbf{k}_{1}\right)+\bar{Q} x_{2}\right]
$$


Proof. Substituting (27) and (28) in (10) and (11), and using the market clearing condition (13), we obtain the equilibrium price function in terms of $\alpha_{1}, \alpha_{2}$, and $\beta$ :

$$
\begin{aligned}
& p=a_{2} \rho\left[r_{2}\left(\mathbf{a}^{\top} \hat{\mathbf{V}}_{\mathrm{z}} \mathrm{a}+V_{\epsilon}\right)\left[\alpha_{1}^{2}\left(1-\rho_{x}^{2}\right)+\beta^{2}\right]+r_{2} a_{2}^{2} \alpha_{1}^{1} \rho^{2}\left(1-\rho_{x}^{2}\right)\right] R^{-1} s \\
& -r_{1} \mathbf{a}^{\top} \hat{\mathbf{V}}_{\mathbf{z}} \mathbf{k}_{1}\left[r_{2}\left(\mathbf{a}^{\top} \hat{\mathbf{V}}_{\mathrm{z}} \mathbf{a}+V_{\epsilon}\right)\left[\alpha_{1}^{2}\left(1-\rho_{x}^{2}\right)+\beta^{2}\right]+r_{2} a_{2}^{2} \alpha_{1}^{1} \rho^{2}\left(1-\rho_{x}^{2}\right)\right] R^{-1} x_{1} \\
& -T_{1}\left(\hat{\mathbf{a}}^{\top} \hat{\mathbf{V}}_{\mathrm{z}} \mathbf{a}+V_{\mathrm{\epsilon}}\right)\left[\underline{a}_{2} \beta \rho\left(\alpha_{1} \rho_{m}+\alpha_{2}\right)+r_{2} \mathbf{a}^{\top} \hat{\mathbf{V}}_{\mathrm{z}} \mathbf{k}_{2}\left[\alpha_{1}^{2}\left(1-\rho_{x}^{2}\right)+\beta^{2}\right]\right. \\
& \left.+r_{2} a_{2} k_{22} \alpha_{1}^{2} \rho^{2}\left(1-\rho_{x}^{2}\right)\right] R^{-1} x_{2} \text {. }
\end{aligned}
$$

Now we can solve for $\alpha_{1}, \alpha_{2}$, and $\beta$ by comparing coefficients with (12). (A standard trick here is to first solve for the ratios $\frac{\alpha_{1}}{\beta}$ and $\frac{\alpha_{2}}{\beta}$.) The futures position $\theta_{1}$ is obtained by substituting the conditional expectations (27) and the price function we have just calculated in (10).

LEMMA A.2. The equilibrium expected trading volume in the one-asset economy is

$$
\begin{gathered}
\mathcal{V}=2\left[(2 / \pi)\left(1+\mu^{2}\right)\right]^{\frac{1}{2}} \bar{D}^{-1}[ \\
{\left[r_{1}^{4}\left(1-\rho_{x}^{2}\right)^{2}\left(\overline{\mathbf{a}}^{\top} \hat{\mathbf{V}}_{\mathbf{z}} \mathbf{k}_{1}\right)^{4}\left[\mu^{2} \rho^{2}+r_{1}^{2}\left(\overline{\mathbf{a}}^{\top} \hat{\mathbf{V}}_{\mathbf{z}} \mathbf{k}_{1}\right)^{2}\right]\right.} \\
\left.+\bar{Q}^{2}-2 r_{1}^{3} \rho_{x}\left(1-\rho_{x}^{2}\right)\left(\overline{\mathbf{a}}^{\top} \hat{\mathbf{V}}_{\mathbf{z}} \mathbf{k}_{1}\right)^{3} \bar{Q}\right]^{\frac{1}{2}}
\end{gathered}
$$

Proof. In equilibrium $\left|\theta_{1}\right|=\left|\theta_{2}\right|$. Furthermore, if $X \sim N\left(0, \sigma^{2}\right)$, then $E(|X|)=(2 / \pi)^{\frac{1}{2}} \sigma$. The result now follows from (29).

Lemma A.3. Suppose $\mathbf{A}$ is a symmetric $n \times n$ matrix and $\mathbf{w}$ is an $n$-dimensional normal variate: $\mathbf{w} \sim N(\mathbf{0}, \mathbf{\Sigma}), \mathbf{\Sigma}$ positive definite. Then $E\left[\exp \left(\mathbf{w}^{\top} \mathbf{A} \mathbf{w}\right)\right.$ is well-defined if and only if $(\mathbf{I}-2 \mathbf{\Sigma A})$ is positive definite, and

$$
E\left[\exp \left(\mathbf{w}^{\top} \mathbf{A} \mathbf{w}\right)=|\mathbf{I}-2 \mathbf{\Sigma} \mathbf{A}|^{-\frac{1}{2}} .\right.
$$

Proof.

$$
\begin{aligned}
E\left[\exp \left(\mathbf{w}^{\top} \mathbf{A} \mathbf{w}\right)\right] & =\int_{\boldsymbol{R}^{n}} \exp \left(\mathbf{w}^{\top} \mathbf{A} \mathbf{w}\right)(2 \pi)^{-\frac{n}{2}}|\Sigma|^{-\frac{1}{2}} \exp \left(-\frac{1}{2} \mathbf{w}^{\top} \Sigma^{-1} \mathbf{w}\right) d \mathbf{w} \\
& =\int_{\boldsymbol{R}^{n}}(2 \pi)^{-\frac{n}{2}}|\Sigma|^{-\frac{1}{2}} \exp \left[-\frac{1}{2} \mathbf{w}^{\top}\left(\Sigma^{-1}-2 \mathbf{A}\right) \mathbf{w}\right] d \mathbf{w} \\
& =|\Sigma|^{-\frac{1}{2}}\left|\left(\Sigma^{-1}-2 \mathbf{A}\right)^{-1}\right|^{\frac{1}{2}} \\
& =|\mathbf{I}-2 \mathbf{\Sigma} \mathbf{A}|^{-\frac{1}{2}}
\end{aligned}
$$




\section{REFERENCES}

1. Akerlof, G. A. (1970): “The Market for 'Lemons': Quality Uncertainty and the Market Mechanism," Quarterly Journal of Economics, 84, 488-500.

2. Allen, B. (19̧80): "Geñeral Equilihrium with Rational Expectations," in A. Mas-Colell and W. Hildenbrand (Eds.), Contributions to Mathematical Economics: Essays in Honor of Gerard Debreu. Amsterdam: North-Holland, 1-23.

3. Allen, F. and D. Gale (1989): “Optimal Security Design,” Review of Financial Studies, 1, 229-263.

4. Allen, F. and D. Gale (1990): "Incomplete Markets and Incentives to Set up an Options Exchange," Geneva Papers on Risk and Insurance Theory, 15, 17-46.

5. Allen, F. and D. Gale (1991): "Arbitrage, Short Sales, and Financial Innovation," Econometrica, 59, 1041-1068.

6. Allen, F. and D. Gale (1994): Financial Innovation and Risk Sharing. Cambridge, MA: MIT Press.

7. Anderson, T. W. (1984): An Introduction to Multivariate Statistical Analysis (2nd ed.). New York: Wiley.

8. Bhattacharya, U., P. Reny, and M. Spiegel (1995): "Destructive Interference in an Imperfectly Competitive Multi-Security Market," Journal of Economic Theory, 65, 136-170.

9. Black, D. G. (1986): "Success and Failure of Futures Contracts: Theory and Empirical Evidence," Monograph 1986-1, Monograph Series in Finance and Economics, Graduate School of Business Administration, New York University.

10. Cass, D. (1992): "Incomplete Financial Markets and Indeterminacy of Competitive Equilibria," in J.-J. Laffont (ed.), Advances in Economic Theory: Sixth World Congress, Volume II. Cambridge University Press, Cambridge, U.K.

11. Cuny, C. J. (1993): "The Role of Liquidity in Futures Market Innovations," Review of Financial Studies, 6, 57-78. 
12. Demange, G. and G. Laroque (1995a): "Optimality of Incomplete Markets," Journal of Economic Theory, 65, 218-232.

13. Demange, G. and G. Laroque (1995b): "Private Information and the Design of Securities," Journal of Economic Theory, 65, 233-257.

14. DeMarzo, P. M. and D. Duffie (1995): "Á Liquidity-Basedu Model of Security Design," working paper, Graduate School of Business, Stanford University.

15. Duffie, D. (1992): "The Nature of Incomplete Security Markets," in J.-J. Laffont (ed.), Advances in Economic Theory: Sixth World Congress, Volume II. Cambridge University Press, Cambridge, U.K.

16. Duffie, D and M.O. Jackson (1989): "Optimal Innovation of Futures Contracts," Review of Financial Studies, 2, 275-296.

17. Duffie, D. and R. Rahi (1995): "Financial Market Innovation and Security Design: An Introduction," Journal of Economic Theory, 65, 1-42.

18. Geanakoplos, J. (1990): "An Introduction to General Equilibrium with Incomplete Markets," Journal of Mathematical Economics, 19, 1-38.

19. Hara, C. (1992): "A Characterization and Generic Inefficiency of Transaction-VolumeMaximizing Contracts," working paper, Department of Economics, University of Cambridge.

20. Hirshleifer, J. (1971): "The Private and Social Value of Information and the Reward to Inventive Activity," American Economic Review, 61, 561-574.

21. Laffont, J.-J. (1985): "On the Welfare Analysis of Rational Expectations Equilibria with Asymmetric Information," Econometrica, 53, 1-29.

22. Magill, M. and W. Shafer (1991): "Incomplete Markets," in W. Hildenbrand and H. Sonnenschein (eds.), Handbook of Mathematical Economics, Volume IV. North Holland, 1523-1614.

23. Milgrom, P. and N. Stokey (1982): "Information, Trade, and Common Knowledge," Journal of Economic Theory, 26, 17-27. 
24. Ōhashi , K. (1992): "Efficient Futures Innovation with Small Transaction Fee: Centralization vs Decentralization," working paper, Institute of Socio-Economic Planning, University of Tsukuba.

25. Ōhashi , K. (1994): “Optimal Futures Innovation in a Dynamic Economy," working pâpor, Institute of Socio-Economic Planning, University of Tsukuba.

26. OThashi , K. (1995): "Endogenous Determination of the Degree of Market Incompleteness in Futures Innovation," Journal of Economic Theory, 65, 198-217.

27. Pesendorfer, W. (1995): "Financial Innovation in a General Equilibrium Model," Journal of Economic Theory, 65, 79-116.

28. Radner, R. (1979): "Rational Expectations Equilibrium: Generic Existence and the Information Revealed by Prices," Econometrica, 47, 655-678.

29. Rahi, R. (1995): “Optimal Incomplete Markets with Asymmetric Information," Journal of Economic Theory, 65, 171-197.

30. Rahi, R. (1996): "Adverse Selection and Security Design," Review of Economic Studies (forthcoming).

31. Saloner, G. (1984): "Self-Regulating Commodity Futures Exchanges," in R. Anderson (Ed.), Industrial Organization of Futures Markets. Lexington, MA: Lexington Books.

32. Wang, J. (1994): “A Model of Competitive Stock Trading Volume," Journal of Political Economy, 102, 127-168. 
1. Albert Marcet and Ramon Marimon

Communication, Commitment and Growth. (June 1991) [Published in Joumal of Economic Theory Vol. 58, no. 2, (December 1992)]

2. Antoni Bosch

Economies of Scale, Location, Age and Sex Discrimination in Household Demand. (June 1991) [Published in European Economic Review 35, (1991) 1589-1595]

3. Albert Satorra

Asymptotic Robust Inferences in the Analysis of Mean and Covariance Structures. (June 1991) [Published in Sociological Methodology (1992), pp. 249-278, P.V. Marsden Edt. Basil Blackwell: Oxford \& Cambridge, MA]

4. Javier Andrés and Jaüiñe Garia

Wage Determination in the Spanish Industry. (June 1991) [Published as "Factores determinantes cie iós säläitiva: avidencia para la industria española" in J.J. Dolado et al. (eds.) La industria y el comportamiento de las empresas españolas (Ensayos en homenaje a Gonzalo Mato), Chapter 6, pp. 171-196, Alianza Economia]

5. Alben Marcet

Solving Non-Linear Stochastic Models by Parameterizing Expectations: An Application to Asset Pricing with Production. (July 1991)

6. Albert Marcet

Simulation Analysis of Dynamic Stochastic Models: Applications to Theory and Estimation. (November 1991), 2d. version (March 1993)

[Published in Advances in Econometrics invited symposia of the Sixth World Congress of the Econometric Society (Eds. JJ. Laffont i C.A.

Sims). Cambridge University Press (1994)]

7. Xavier Calsamiglia and Alan Kirman

A Unique Informationally Efficient and Decentralized Mechanism with Fair Outcomes. (November 1991) [Published in Econometrica, vol. 61,5, pp. 1147-1172 (1993)]

8. Albert Satorra

The Variance Matrix of Sample Second-order Moments in Multivariate Linear Relations. (January 1992) [Published in Staristics \& Probability Letters Vol. 15, no. 1, (1992), pp. 63-69]

9. Teresa Garcia-Milà and Therese J. McGuire

Industrial Mix as a Factor in the Growth and Variability of States'Economies. (January 1992) [Published in Regional Science and Urban Economics, vol. 23, (1993) pp. 229-241]

10. Walter Garcia-Fontes and Hugo Hopenhayn

Entry Restrictions and the Determination of Quality. (February 1992)

11. Guillem López and Adam Robert Wagstaff

Indicadores de Eficiencia en el Sector Hospitalario. (March 1992) [Published in Moneda y Crédito Vol. 196]

12. Daniel Serra and Charles ReVelle

The PQ-Median Problem: Location and Districting of Hierarchical Facilities. Part I (April 1992) [Published in Location Science, Vol. 1 , no. 4 (1993)]

13. Daniel Serra and Charles ReVelle

The PQ-Median Problem: Location and Districting of Hierarchical Facilities. Part II: Heuristic Solution Methods. (April 1992) [Published in Location Science, Vol. 2, no. 2 (1994)]

14. Juan Pablo Nicolini

Ruling out Speculative Hyperinflations: a Game Theoretic Approach. (April 1992) [Forthcoming in Joumal of Economic Dynamics and Control]

15. Albert Marcet and Thomas J. Sargent

Speed of Convergence of Recursive Least Squares Learning with ARMA Perceptions. (May 1992) [Forthcoming in Leaming and Rationality in Economics]

16. Albert Satorra

Multi-Sample Analysis of Moment-Structures: Asymptotic Validity of Inferences Based on Second-Order Moments. (June 1992) [Published in Statistical Modelling and Latent Variables Elsevier, North Holland. K.Haagen, D.J.Bartholomew and M. Deistler (eds.), pp. 283-298.]

Special issue Vernon L. Smith

Experimental Methods in Economics. (June 1992)

17. Albert Marcet and David A. Marshall

Convergence of Approximate Model Solutions to Rational Expectation Equilibria Using the Method of Parameterized Expectations.

18. M. Antònia Monés, Rafael Salas and Eva Ventura

Consumption, Real after Tax Interest Rates and Income Innovations. A Panel Data Analysis. (December 1992)

19. Hugo A. Hopenhayn and Ingrid M. Werner

Information, Liquidity and Asset Trading in a Random Matching Game. (February 1993) 
20. Daniel Serra

The Coherent Covering Location Problem. (February 1993) [Forthcoming in Papers in Regional Science]

21. Ramon Marimon, Stephen E. Spear and Shyam Sunder

Expectationally-driven Market Volatility: An Experimental Study. (March 1993) [Forthcoming in Joumal of Economic Theory]

22. Giorgia Giovannetti, Albert Marcet and Ramon Marimon

Growth, Capital Flows and Enforcement Constaints: The Case of Africa. (March 1993) [Published in European Economic Review 37, pp. 418-425 (1993)]

23. Ramon Marimon

Adaptive Learning, Evolutionary Dynamics and Equilibrium Selection in Games. (March 1993) [Published in European Economic Review 37 (1993)]

24. Ramon Marimon and Ellen McGrattan

On Adaptive Learning in Strategic Games. (fíǟich ! 1003) [Forthonming in A. Kiman and M. Salmon eds. "Learning and Rationality in Economics" Basil Blackwell]

25. Ramon Marimon and Shyam Sunder Indeterminacy of Equilibria in a Hyperinflationary World: Experimental Evidence. (March 1993) [Forthcoming in Econometrica]

26. Jaume Garcia and José M. Labeaga

A Cross-Section Model with Zeros: an Application to the Demand for Tobacco. (March 1993)

27. Xavier Freixas

Short Term Credit Versus Account Receivable Financing. (March 1993)

28. Massimo Motta and George Norman

Does Economic Integration cause Foreign Direct Investment? (March 1993) [Published in Working Paper University of Edinburgh 1993:I]

29. Jeffrey Prisbrey

An Experimental Analysis of Two-Person Reciprocity Games. (February 1993) [Published in Social Science Working Paper 787 (November 1992)]

30. Hugo A. Hopenhayn and Maria E. Muniagurria

Policy Variability and Economic Growth. (February 1993)

31. Eva Ventura Colera

A Note on Measurement Error and Euler Equations: an Alternative to Log-Linear Approximations. (March 1993) [Published in Economics Letters, 45, pp. 305-308 (1994)]

32. Rafael Crespi i Cladera

Protecciones Anti-Opa y Concentración de la Propiedad: el Poder de Voto. (March 1993)

33. Hugo A. Hopenhayn

The Shakeout. (April 1993)

34. Walter Garcia-Fontes

Price Competition in Segmented Industries. (April 1993)

35. Albert Satorra i Brucart

On the Asymptotic Optimality of Alternative Minimum-Distance Estimators in Linear Latent-Variable Models. (February 1993) [Published in Econometric Theory, 10, pp. 867-883]

36. Teresa Garcia-Milà, Therese J. McGuire and Robert H. Porter

The Effect of Public Capital in State-Level Production Functions Reconsidered. (February 1993) [Forthcoming in The Review of Economics and Statistics]

37. Ramon Marimon and Shyam Sunder

Expectations and Learning Under Alternative Monetary Regimes: an Experimental Approach. (May 1993)

38. José M. Labeaga and Angel López

Tax Simulations for Spain with a Flexible Demand System. May 1993)

39. Daniel Serra and Charles ReVelle

Market Capture by Two Competitors: The Pre-Emptive Location Problem. (May 1993) [Published in Joumal of Regional Science, Vol. 34, no.4 (1994)]

40. Xavier Cuadras-Morató

Commodity Money in the Presence of Goods of Heterogenous Quality. (July 1993) [Published in Economic Theory 4 (1994)]

41. M. Antònia Monés and Eva Ventura

Saving Decisions and Fiscal Incentives: A Spanish Panel Based Analysis. (July 1993)

42. Wouter J. den Haan and Albert Marcet

Accuracy in Simulations. (September 1993) [Published in Review of Economic Studies, (1994)] 
43. Jordi Gali

Local Externalities, Convex Adjustment Costs and Sunspot Equilibria. (September 1993) [Forthcoming in Joumal of Economic Theory]

44. Jordi Galí

Monopolistic Competition, Endogenous Markups, and Growth. (September 1993) [Fonthcoming in European Economic Review]

45. Jordi Galí

Monopolistic Competition, Business Cycles, and the Composition of Aggregate Demand. (October 1993) [Forthcoming in Joumal of Economic Theoryl

46. Oriol Amat

The Relationship between Tax Regulations and Financial Accounting: a Comparison of Germany, Spain and the United Kingdom. (November 1993) [Forthcoming in European Management Joumal]

47. Diego Rodríguez and Dimitri Vayanos

Decentralization and the Managenienit of Competition. November 1993)

48. Diego Rodriguez and Thomas M. Stoker

A Regression Test of Semiparametric Index Model Speciication. (November 1993)

49. Oriol Amat and John Blake

Control of the Costs of Quality Management: a Review or Current Practice in Spain. (November 1993)

50. Jeffrey E. Prisbrey

A Bounded Rationality, Evolutionary Model for Behavior in Two Person Reciprocity Games. (November 1993)

51. Lisa Beth Tilis

Economic Applications of Genetic Algorithms as a Markov Process. (November 1993)

52. Ángel López

The Comand for Private Transport in Spain: A Microeconometric Approach. (December 1993)

53. Ángel López

An Assessment of the Encuesta Continua de Presupuestos Familiares (1985-89) as a Source of Information for Applied Reseach. (December 1993)

54. Antonio Cabrales

Stochastic Repiicator Dynamics. (December 1993)

55. Antonio Cabrales and Takeo Hoshi

Heterogeneous Beliefs, Wealth Accumulation, and Asset Price Dynamics. (February 1993, Revised: June 1993) [Forthcoming in Joumal of Economic Dynamics and Control]

56. Juan Pablo Nicolini

More on the Time Inconsistency of Optimal Monetary Policy. (November 1993)

57. Lisa $B$. Tilis

Income Distribution and Growth: A Re-examination. (December 1993)

58. José Maria Marin Vigueras and Shinichi Suda

A Model of Financial Markets with Default and The Role of "Ex-ante" Redundant Assets. (January 1994)

59. Angel de la Fuente and José Maria Marín Vigueras

Innovation, "Bank" Monitoring and Endogenous Financial Development. (January 1994) [Finance and Banking Discussion Papers Series (10)]

60. Jordi Galí

Expectations-Driven Spatial Fluctuations. (January 1994)

61. Josep M. Argilés

Survey on Commercial and Economic Collaboration Between Companies in the EEC and Former Eastern Bloc Countries. (February 1994) [Published in Revista de Estudios Europeos n 8 (1994) pp. 21-36]

62. German Rojas

Optimal Taxation in a Stochastic Growth Model with Public Capital: Crowding-in Effects and Stabilization Policy. (September 1993)

63. Irasema Alonso

Patterns of Exchange, Fiat Money, and the Welfare Costs of Inflation. (November 1991, Revised: September 1993)

64. Rohit Rahi

Adverse Selection and Security Design. (July 1993, Revised: February 1994)

65. Jordi Gali and Fabrizio Zilibotti

Endogenous Growth and Poverty Traps in a Coumotian Model. (November 1993)

66. Jordi Gali and Richard Clarida

Sources of Real Exchage Rate Fluctuations: How Important are Nominal Shocks?. (October 1993, Revised: January 1994) [Forthcoming

in Carmegie-Rochester Conference in Public Policy] 
67. John Ireland

A DPP Evaluation of Efficiency Gains from Channel-Manufacturer Cooperation on Case Counts. (February 1994)

68. John Ireland

How Products' Case Volumes Influence Supermarket Shelf Space Allocations and Profits. (February 1994)

69. Fabrizio Zilibotti

Foreign Investments, Enforcement Constraints and Human Capital Accumulation. (February 1994)

70. Vladimir Marianov and Daniel Serra

Probabilistic Maximal Covering Location Models for Congested Systems. (March 1994)

71. Giorgia Giovannetti.

Import Pricing, Domestic Pricing and Market Structure. (August 1993, Revised: January 1994)

72. Raffaela Giordano.

A Model of Inflation and Reputation with Wage Bargaining. (November 1992, Revised March 1994)

73. Jaume Puig i Junoy.

Aspectos Macroeconómicos del Gasto Sanitario en el Proceso de Convergencia Europea. (Enero 1994)

74. Daniel Serra, Samuel Ratick and Charles ReVelle.

The Maximum Capture Problem with Uncertainly (March 1994) [Forthcoming in Environment and Planning B]

75. Oriol Amat, John Blake and Jack Dowds.

Issues in the Use of the Cash Flow Statement-Experience in some Other Countries (March 1994) [Forthcoming in Revista Española de Financiación y Contabilidad]

76. Albert Marcet and David A. Marshall.

Solving Nonlinear Rational Expectations Models by Parameterized Expectations: Convergence to Stationary Solutions (March 1994)

77. Xavier Sala-i-Martin

Lecture Notes on Economic Growth (I): Introduction to the Literature and Neoclassical Models (May 1994)

78. Xavier Sala-i-Martin.

Lecture Notes on Economic Growth (II): Five Prototype Models of Endogenous Growth (May 1994)

79. Xavier Sala-i-Martin.

Cross-Sectional Regressions and the Empirics of Economic Growth (May 1994)

80. Xavier Cuadras-Morató.

Perishable Medium of Exchange (Can Ice Cream be Money?) (May 1994)

81. Esther Martinez Garcia.

Progresividad y Gastos Fiscales en la Imposición Personal sobre la Renta (Mayo 1994)

82. Robert J. Barro, N. Gregory Mankiw and Xavier Sala-i-Martin.

Capital Mobility in Neoclassical Models of Growth (May 1994)

83. Sergi Jiménez-Martin.

The Wage Setting Process in Spain. Is it Really only about Wages? (April 1993, Revised: May 1994)

84. Robert J. Barro and Xavier Sala-i-Martin.

Quality Improvements in Models of Growth (June 1994)

85. Francesco Drudi and Raffaela Giordano.

Optimal Wage Indexation in a Reputational Model of Monetary Policy Credibility (February 1994)

86. Christian Helmenstein and Yury Yegorov.

The Dynamics of Migration in the Presence of Chains (June 1994)

87. Walter García-Fontes and Massimo Motta.

Quality of Professional Services under Price Floors. (June 1994) [Forthcoming in Revista Española de Economía]

88. Jose M. Bailen.

Basic Research, Product Innovation, and Growth. (September 1994)

89. Oriol Amat and John Blake and Julia Clarke.

Bank Financial Analyst's Response to Lease Capitalization in Spain (September 1994) [Forthcoming in Intemational Joumal of Accounting.]

90. John Blake and Oriol Amat and Julia Clarke.

Management's Response to Finance Lease Capitalization in Spain (September 1994) [Published in Intermational Joumal of Accounting, vol. 30, pp. 331-343 (1995)]

91. Antoni Bosch and Shyam Sunder.

Tracking the Invisible Hand: Convergence of Double Auctions to Competitive Equilibrium. (Revised: July 1994) 
92. Sergi Jiménez-Martin

The Wage Effect of an Indexation Clause: Evidence from Spanish Manufacturing Firms. (August 1993, Revised: September 1994)

93. Albert Carreras and Xavier Tafunell.

National Enterprise. Spanish Big Manufacturing Firms (1917-1990), between State and Market (September 1994)

94. Ramon Fauli-Oller and Massimo Motta.

Why do Owners let their Managers Pay too much for their Acquisitions? (October 1994)

95. Marc Sáez Zafra and Jorge V. Pérez-Rodriguez.

Modelos Autorregresivos para la Varianza Condicionada Heteroscedástica (ARCH) (October 1994)

96. Daniel Serra and Charles ReVelle.

Competitive Location in Discrete Space (November 1994) [Forthcoming in Zvi Drezner (ed.): Facility Location: a Survey of Applications and Methods. Springer-Verlag New York.

97. Alfonso Gambardella and Walter Garcia-Fontes.

Regional Linkages through European Research Funding (October 1994) [Forhbcoming in Economic of Innovation and New Technology]

98. Daron Acemoglu and Fabrizio Zilibotti.

Was Prometheus Unbound by Chance? Risk, Diversification and Growth (November 1994)

99. Thierry Foucault.

Price Formation and Order Placement Strategies in a Dynamic Order Driven Market (Revised: June 1994) Finance and Banking

Discussion Papers Series (2)]

100. Ramon Marimon and Fabrizio Zilibotti

'Actual' versus 'Virtual' Employment in Europe: Why is there Less Employment in Spain? (December 1994)

101. María Sáez Martí.

Are Large Windows Efficient? Evolution of Learning Rules in a Bargaining Model (December 1994)

102. Maria Sáez Martí.

An Evolutionary Model of Development of a Credit Market (December 1994)

103. Walter Garcia-Fontes and Ruben Tansini and Marcel Vaillant.

Cross-Industry Entry: the Case of a Small Developing Economy (December 1994)

104. Xavier Sala-i-Martin.

Regional Cohesion: Evidence and Theories of Regional Growth and Convergence (October 1994)

105. Antoni Bosch-Domènech and Joaquim Silvestre.

Credit Constraints in General Equilibrium: Experimental Results (December 1994)

106. Casey B. Mulligan and Xavier Sala-i-Martin.

A Labor-Income-Based Measure of the Value of Human Capital: an Application to the States of the United States. (March 1994, Revised: December 1994)

107. José M. Bailén and Luis A. Rivera-Bátiz.

Human Capital, Heterogeneous Agents and Technological Change (March 1995)

108. Xavier Sala-i-Martin.

A Positive Theory of Social Security (Revised: February 1995)

109. J. S. Marron and Frederic Udina.

Interactive Local Bandwidth Choice (February 1995)

110. Marc Sáez and Robert M. Kunst.

ARCH Patterns in Cointegrated Systems (March 1995)

111. Xavier Cuadras-Morató and Joan R. Rosés.

Bills of Exchange as Money: Sources of Monetary Supply during the Industrialization in Catalonia (1844-74) (April 1995)

112. Casey B. Mulligan and Xavier Sala-i-Martin

Measuring Aggregate Human Capital (October 1994, Revised: January 1995)

113. Fabio Canova.

Does Detrending Matter for the Determination of the Reference Cycle and the Selection of Tuming Points? (February 1994, Revised: March 1995)

114. Sergiu Hart and Andreu Mas-Colell.

Bargaining and Value (July 1994, Revised: February 1995) [Forthcoming in Econometrica]

115. Teresa Garcia-Milà, Albert Marcet and Eva Ventura.

Supply Side Interventions and Redistribution (June 1995)

116. Robert J. Barro and Xavier Sala-i-Martin.

Technological Diffusion, Convergence, and Growth (May 1995) 
117. Xavier Sala-i-Martin.

The Classical Approach to Convergence Analysis (June 1995)

118. Serguei Maliar and Vitali Perepelitsa.

LCA Solvability of Chain Covering Problem (May 1995)

119. Serguei Maliar, Igor' Kozin and Vitali Perepelitsa.

Solving Capability of LCA (June 1995)

120. Antonio Ciccone and Robert E. Hall.

Productivity and the Density of Economic Activity (May 1995) [Forthcoming in American Economic Review]

121. Jan Werner.

Arbitrage, Bubbles, and Valuation (April 1995)

122. Andrew Scott.

Why is Consumption so Seasonal? (March 1995)

123. Oriol Amat and John Blake.

The Impact of Post Industrial Society on the Accounting Compromise-Experience in the UK and Spain (July 1995)

124. William H. Dow, Jessica Holmes, Tomas Philipson and Xavier Sala-i-Martin.

Death, Tetanus, and Aerobics: The Evaluation of Disease-Specific Health Interventions (July 1995)

125. Tito Cordella and Manjira Datta.

Intertemporal Cournot and Walras Equilibrium: an Illustration (July 1995)

126. Albert Satorra.

Asymptotic Robustness in Multi-Sample Analysis of Multivariate Linear Relations (August 1995)

127. Albert Satorra and Heinz Neudecker.

Compact Matrix Expressions for Generalized Wald Tests of Equality of Moment Vectors (August 1995)

128. Marta Gómez Puig and José G. Montalvo.

Bands Width, Credibility and Exchange Risk: Lessons from the EMS Experience (December 1994, Revised: June 1995) [Finance and Banking Discussion Papers Series (1)]

129. Marc Sáez.

Option Pricing under Stochastic Volatility and Stochastic Interest Rate in the Spanish Case (August i995) fFinance and Banking Discussion Papers Series (3)]

130. Xavier Freixas and Jean-Charles Rochet.

Fair Pricing of Deposit Insurance. Is it Possible? Yes. Is it Desirable? No (January 1995, Revised: June 1995) [Finance and Banking Discussion Papers Series (4)]

131. Heinz Neudecker and Albert Satorra.

The Algebraic Equality of Two Asymptotic Tests for the Hypothesis that a Normal Distribution Has a Specified Correlation Matrix (April 1995)

132. Walter Garcia-Fontes and Aldo Geuna.

The Dynamics of Research Networks in Brite-Euram (January 1995, Revised: July 1995)

133. Jeffrey S. Simonoff and Frederic Udina.

Measuring the Stability of Histogram Appearance when the Anchor Position is Changed (July 1995) [Forthcoming in Computational Statistics and Data Analysis]

134. Casey B. Mulligan and Xavier Sala-i-Martin.

Adoption of Financial Technologies: Implications for Money Demand and Monetary Policy (August 1995) [Finance and Banking Discussion Papers Series (5)]

135. Fabio Canova and Morten O. Ravn.

International Consumption Risk Sharing (March 1993, Revised: June 1995) [Finance and Banking Discussion Papers Series (6)]

136. Fabio Canova and Gianni De Nicolo'.

The Equity Premium and the Risk Free Rate: A Cross Country, Cross Maturity Examination (April 1995) Finance and Banking Discussion Papers Series (7)]

137. Fabio Canova and Alber Marcet.

The Poor Stay Poor: Non-Convergence across Countries and Regions (October 1995)

138. Etsuro Shioji.

Regional Growth in Japan (January 1992, Revised: October 1995)

139. Xavier Sala-i-Martin.

Transfers, Social Safety Nets, and Economic Growth (September 1995)

140. José Luis Pinto.

Is the Person Trade-Off a Valid Method for Allocating Health Care Resources? Some Caveats (October 1995) 
141. Nir Dagan.

Consistent Solutions in Exchange Economies: a Characterization of the Price Mechanism (November 1995)

142. Antonio Ciccone and Kiminori Matsuyama

Start-up Costs and Pecuniary Externalities as Barriers to Economic Development (March 1995) [Forthcoming in Joumal of Development Economics]

143. Etsuro Shioji.

Regional Allocation of Skills (December 1995)

144. José V. Rodríguez Mora.

Shared Knowledge (September 1995)

145. José M. Marín and Rohit Rahi.

Information Revelation and Market Incompleteness (February 1996) [Finance and Banking Discussion Papers Series (8)] 